\title{
Overlooking the Obvious: How to Use Semiotics and Metaphors to Reinforce E-Learning
}

\author{
Ruth Gannon Cook ${ }^{*}$ \\ DePaul University, Chicago, IL., United States
}

\begin{tabular}{|c|c|}
\hline \multicolumn{2}{|c|}{ University of Houston Clear Lake, Houston, TX., United States } \\
\hline Article history & This article addresses the historic and cultural influences of semiotics on \\
\hline $\begin{array}{l}\text { Received: } \\
04.01 .2015\end{array}$ & human learning. In reviewing over thirty studies conducted since the \\
\hline $\begin{array}{l}\text { Received in revised form: } \\
19.12 .2015\end{array}$ & $\begin{array}{l}\text { have positively influenced student's learning. These studies suggest a } \\
\text { critical role of semiotics in higher education courses taught in online } \\
\text { learning environments. Semiotic tools can positively influence students in }\end{array}$ \\
\hline $\begin{array}{l}\text { Accepted: } \\
21.12 .2015\end{array}$ & $\begin{array}{l}\text { online courses, as in the cases where course completion rates of courses } \\
\text { containing strategic semiotic elements were higher than comparable }\end{array}$ \\
\hline Key words: & online courses without those semiotic elements. The implications for \\
\hline $\begin{array}{l}\text { Semiotics, online learning, } \\
\text { instructional design, qualitative }\end{array}$ & $\begin{array}{l}\text { course design is the inclusion of strategic semiotic elements as part of } \\
\text { course design addressing content, system navigation, and technologies to } \\
\text { deliberately and intentionally plan semiotic features that appeal and not } \\
\text { alienate reluctant online students. Features which bridge students' prior } \\
\text { knowledge and cultural contexts to new content materials and academic } \\
\text { success should be considered to better enlist and retain learners. } \\
\text { Observing successful semiotic marketing practices could shed light on } \\
\text { how these tools could be best incorporated into online courses and } \\
\text { provide important cultural elements to mediate new learning. Ultimately, } \\
\text { more than technology, management systems, and content should be } \\
\text { studied when working with online students; human factors, like historic } \\
\text { and cultural experiences, must also be considered. }\end{array}$ \\
\hline
\end{tabular}

\section{Introduction}

The quest for more effective ways to help online learners complete online courses and degree programs has generated incorporation of many new technologies and social media in higher education (Sharples, Addison, Ferguson, 2013, p.17). While increased interactivities and social applications have improved retention, attrition rates remain high (Ross, Kena, Rathbun, Kewal, 2012, p.184), especially among high risk groups, and particularly in the United States. This research addresses how retention could be improved by cueing with semiotic tools made available to learners entering online courses. While this research cannot be generalizable globally because each country has many cultures with their own cues, there are still some cues that are almost recognizable globally. Using cultural cues that consist of pictures, symbols, and metaphors provide a first hint that more information is coming that is 
recognizable and sends signals to beckon the learners to continue onward through the course. If these signposts are present, learners' anxieties seem to diminish ( $\mathrm{Yu}, 2013$; Ley and Gannon Cook, 2013), but without these key elements many students' angst increases, particularly for at-risk or low socio-economic students, leaving them feeling uncomfortable without those signposts or "breadcrumbs" to help direct them through the course.

Recent research (Gannon-Cook, in press; Owen, 2014; Pinto, 2014; Tochon, 2013: Youngs, Serafini, 2013) suggests the strategic use of semiotics can improve learner comprehension and minimize cognitive load. Just as websites link to similar sites, semiotic tools like storytelling and learners sharing their stories can help them stay on track through the course. Their narratives and their ongoing reactions inform the instructor of their progress through the course and help frame quick instructor responses and interventions to assist learners who may have become confused or lost. What the learners say and their reactions provide clues and the psychological "glue" that help them mediate their knowledge with course materials subconsciously which often helps them to let down some barriers and be more receptive to the new course materials. Learners serve as their own agents of change and one they find them they continue to follow the semiotic breadcrumbs that lead them onward to persevere and stay the course to completion.

As more students are directed online it becomes more imperative than ever to move beyond a one story, one learning management system, to seek ways to enrich and nurture students' cultures and experiences by encouraging their stories and prior knowledge (Behizadeh, 2014). There is no single "one" story or panacea to increasing retention, so it's time that researchers and instructional designers "widen the net" by looking at interventions that successfully use the cultural anchors of semiotics to adopt electronic innovations, such as linguistics and marketing.

\section{Linguistics, Mathematics, and Reading}

The most basic definition of semiotics is that it is "the study of signs and symbols and how they are used" (Merriam-Webster Dictionary, 2015, online). We wanted to go back in time and conduct interdisciplinary research to see if there were any records of studies on semiotics used as mediation tools. As we began our study we quickly realized that there is a history of using symbols, pictures and metaphors in disciplines where we would expect to find semiotics, like linguistics. We began to uncover studies where semiotics were used to facilitate and supplement learning across a broader array of other academic disciplines to help students with reading or Mathematics, or to help link new concepts together for learners (Anstey, 1988; Barthes, 1977; Cowan, and Albers, 2006; deVito, 2009; Gallini, Seaman, and Terry, 1995; Gregory, Arenheim, Goodman and Gombrich, 1997; Kress, and van Leeuwen. 1996; O'Neil, 2011; Wade, and Adams, 1990). There were studies of semiotics utilized in teaching subjects perceived as somewhat challenging, such as Mathematics (Cobb, Yackel, and Wood, 1992; DePriter, 2013; Ford, 1999; Moreno-Armella, 1999), which looked at the contextual nature of teaching Mathematics using narratives and graphics instruction, but primarily in elementary (second grade) students. One study researched the use of semiotics in the sciences (Ford, 1999) which studied visual representations as conceptual science bridges to help sixth-graders learn important science theories.

But there was no one focal place or academic discipline that housed seminal research studies on the topic of semiotics. Also, most research on the topic of semiotics was at least fifteen or more years old. It appeared that, based on these older studies, the quest to find out if semiotic 
tools, like graphics and narratives, could benefit learners was largely bypassed as the research emphasis moved on to study the benefits of technology tools and social media.

\section{Excavating Semiotic Vestiges}

The study of semiotics in academia has largely been relegated to linguistics and marketing. But there are interdisciplinary studies that date back to far earlier than the 1980s. In fact, semioticians like Charles Sanders Peirce $(1931-1935,1960)$ and Ferdinand deSaussure (1916/1983), presented general theories of human communication studying the relationships created by signs and symbols. They posited that people responded to their understanding of reality indirectly through filters of their perception of objects, actions and patterns around and confronting them, not just of physical space. Seminal studies of semiotics predating laptop computers dating back to the 1950s provided seminal insights into the importance of semiotic tools (Arnheim, 1954, 1969, 1974, 1986; Dwyer, 1967, 1969, 1972, 1975, 1978, 1987; Eco, 1976, 1979a,b, 1984, 1986, 1997; Eco and Seboek, 1984; Fleming, 1967, 1993; Gardner, 1982; Gardner and Perkins, 1974; Gombrich, 1969; Kennedy, 1974; Kennedy, 1984a, 1984b; Knowlton, 1964; Kosslyn, 1980, 1981; Levie, 1978, 1987; Levie and Dickie, 1973; Levie and Lentz, 1982; Levin, Anglin, and Carner, 1987; Miller, 1938; Peirce, 1960; Stone and Glock, 1981; Vernon, 1953). Barthes' Image/Music/Text (1977), and Blumer's Symbolic Interactionism (1969), both looked at how language and symbols give meaning to life experiences and constructions, as well as how patterns created by interactions create our experiences. Studies, like that of Anglin, Towers, and Levie (1987) provide key findings on the positive impact of strategic visual message design and the role of dynamic illustrations to motivate and influence learning. Later, Kress and van Leeuwen (1996) studied the grammar of visual design and how images successfully conveyed meaning and intentional messaging.

All of these studies focused on pictures, animations, icons, graphs and charts to assess the impact of these tools on participants and, while almost all of these studies indicated there were positive impacts resulting from the use of the semiotics, many fell into oblivion because of the lack of consistency in reporting the methodologies employed in those studies. The studies did, however, present data and findings that could provide the groundwork for further research on how semiotics might reinforce new concepts and learning.

We conducted research studies on semiotic tools and whether the use of semiotics may be useful to help students find their way using graphics and metaphors as signposts to show the path to their course destinations (Ley and Gannon-Cook, 2014a, 2014b). We wanted to excavate interdisciplinary data conducted over the last fifty years that, heretofore, may not have been unearthed due to lack of access. Now, with the advantages of interdisciplinary virtual archives, we were able to unearth studies that could provide important insights into how semiotic tools might work effectively to facilitate and mediate learning. Our goal was to find seminal research that might reveal whether semiotic tools had been utilized effectively in the past fifty years across academic disciplines and provide a historic study that documented those studies.

\section{Frozen: Metaphors and Stories Are Integral to Conceptual Thinking}

There are a number of aspects of semiotics, only some of which are attributed to the definition of semiotics, such as signs, symbols, and pictures. Many other forms of semiotics exist, such as text, mathematical symbols, stories and legends, and proxemics in the forms of 
technologies. Forms of semiotics pervade our day-to-day lives, imperceptibly communicating and mediating with our prior knowledge in the forms of advertising signs and symbols to affect so many of our daily choices and decisions, but also communicating through metaphors and stories.

\section{Metaphors.}

"A metaphor is a figure of speech which attributes a similar quality or name to something to show or suggest they are similar; an object, activity, symbol, or idea used to represent something else" (Merriam-Webster Dictionary, 2015, online).

Lakoff and Johnson (1980) posed that metaphors are pervasive, "not just in language, but in thought and action" (p.3) because how we think and act are fundamentally metaphorical; metaphors guide our functions, concepts, and even guide our relationships. But metaphors are so ubiquitous that we think and act using them automatically. They used language as a primary example and also provided examples, such as, how metaphors structure everyday activities. One example is what he calls the "Argument is War" example (p.4) where war phrases are used, like,
Your claims are indefensible.
He attacked every weak point in the argument.
I demolished his argument.
He shot down all my arguments.(p.4)

Lakoff's point was that we don't just talk about arguments as war, we actually win or lose arguments like a battle. Another metaphor is "Time is Money" (p.7), where the value of time is conveyed in monetary phrases, such as,

You're wasting my time.

This will save you time.

How did you spend your time?

That mistake cost me an hour.

I'm running out of time.

Thank you for your time. (p.7-8)

Again, in a similar fashion to how we have adopted the metaphor of war for arguing, we have attributed the value ascribed to money to time. How we conceptualize ideas and events is characterized according to our cultures and the use of our language, both of which are characterized by metaphorical concepts. In fact, Lakoff holds that "the most fundamental values in a culture will be coherent with the metaphorical structure of the most fundamental concepts in the culture" (p.22). Metaphors allow humans to make sense of the world in human terms that make sense to most others. Lakoff provides numerous examples of theories, presenting these as "foundations", "support structures", and "solid foundations" (p.46). He poses ideas can be like people that "give birth to other ideas", "plant seeds", "bear fruit", "produce fertile imagination", and that ideas become commodities that "are packaged or are marketable"; or can be resources, "an idea lightbulb", or "a treasure trove" (p.48). He poses the question, "are there any concepts that are understood directly without metaphor?"(p.56).

By reasoning through metaphors, anchoring of information occurs that facilitates understanding of new ideas (Gallini, Seaman, Terry, 1995). Vico (Danesi, 1993; Miner, 2002; Verene, 1993) pointed to the metaphor as the crucial factor in the development of language. 
Even Skinner felt metaphors had a strong impact on society and included them in his overall theory of verbal behaviour (1983). These studies provided findings to support hypotheses that metaphors were not alternatives to literal language but were already embedded in iconic thought. Metaphors over time became frozen, absorbed, into daily language. Metaphors filled conceptual gaps; and metaphors could take on a literal quality as a part of that culture. The metaphor has been acknowledged as a tool that provides an almost universal conceptualization of basic human tendencies (1993). In the evolving group of global metaphors, virtual webs, navigation systems, simulated galleries, all demonstrate how metaphors have been incorporated into our technologies. And the use of icons in technology applications, such as, trash cans, open doors, chat rooms, homes, file folders, and paint palettes, all conjure almost-universal responses from a growing group of global cybercitizens.

A classic example of an often-quoted metaphor is the metaphor of Plato's cave. To those imprisoned in the cave, the shadows they see on the walls are reality since those shadows are all they know. They have never been outside the cave. Should one person escape outside of the cave, he then understands he was only seeing shadows on the cave walls. (This metaphor prompted us as researchers to think maybe our "cave" as instructional designers is a virtual one that surrounds online course design consisting of the learning management systems, software applications and social media.)

The sociocultural tool of metaphor has been and will continue to be extended into virtually every area of society, including education. Vygotsky used the metaphor of "the vines" which spread out and grow cultural, environmental, disciplined, and authoritative knowledge. He used vines to describe how the child's spontaneous concepts grow upward as language and experience develop instruction and grow downward as the child learns scientific concepts and moves from abstraction to a more concrete level of understanding (Fernlund, 1995).

Another popular metaphor uses a "landscape" to describe the need for a map to find one's location and direction, and, perhaps if lost, the need to find an entirely new map. "What comes across over and over again in studying these ideas is that metaphorically, the mapmakers are part of the landscape being mapped (Fernlund, 1995, p.117). This metaphor is particularly relevant to the use of technology in education. Teachers may well require "new maps" just to learn the terrain of technology and integrating it into what they teach, but they may also need to create new knowledge maps that integrate the old knowledge with new knowledge and technologies. In so doing, they would still maintain the educational landscape being mapped, but they would include the mental topography that allow students to navigate and arrive at their destination of learning the course materials. We as researchers felt it was time to put traditional and virtual tools together in the design of online courses to see if online students could follow semiotic maps as they do with following GPS directions to arrive at their online course completions successfully.

\section{Stories or Legends.}

Stories are often told as metaphors, and stories often include aspects of fables, legends, narrations and tales, all of which play a part in the successful understanding of important moral lessons and cultural legacies. Stories and narratives are methods of delivery that have good control of symbols since the stories encompass the verbiage, pictures, and text that comprise them. They can include details in a story form that offer history and principles of truth in a "functional act of cultural memory" (Verene, 1993, p.13); narratives provide 
satisfaction in the telling of the thing in words and connecting to the metaphorical power of language. Narration includes culture, which at its origins contains narration as myth and oral tradition, and completes a kind of loop that both begins and ends with itself.

Harvard's Gerald Zaltman (Zaltman and Colter, 1995; Zaltman, 1997, Zaltman and Zaltman, 2008) poses that symbols, metaphors, and legends are deeply embedded in our psyche; they provide the basic foundations for the brand stories created in marketing. Product marketers look for the symbols, metaphors, and stories that resonate with consumers because they need to know which deep metaphors affect them positively. They leverage them in advertising, packaging, and product design, and make them fundamental building blocks for developing comprehensive ad campaigns and cementing customer relationships. From his studies, Zaltman purports when there is a high failure rate of new products or existing products to achieve expected goals, it suggests that the marketers have not thought deeply enough about how their customers actually think (Gannon-Cook and Ley, 2015; Zaltman, 2008). He suggests using deep metaphors and testimonials, stories, of customers to enlist and retain them. We wondered whether these same approaches might work similarly in the enlistment and retention of our students in online courses.

\section{Stories and Legends}

Oswald (2012) maintains there are symbolic needs of consumers that need to be met and targeting how to meet those needs forms the basis for finding solutions to meet them. In the case of consumer marketing, the solutions are met through consumers choosing goods or making purchasing decisions to satisfy those needs. Over the last thirty years Oswald (1984, 1996, 2010) conducted marketing research on buying patterns of consumers and focused on the use of semiotics to enlist and retain customers. In looking at the characteristics of the consumers in those studies it reminded us that our students not only had most of the same characteristics as those consumers, but, in fact, were both consumers and students.

Semiotics, according to Oswald, identifies ways brand meanings are embedded in the broad cultural myths, social organization, and beliefs of the target market: "(Semiotics) aligns the brand meaning and positioning with consumers' personal, social, and cultural needs and expectations" (Oswald, 2012, p.50).

But marketing semiotics differs from academic semiotics in that academic semiotics uses signs, symbols, metaphors, as facilitative tools; the academic is concerned with theory building, hypothesis testing, and the cultural critique as ends in themselves. The marketing semiotician "uses theory, method and cultural critique to align brands with the culture of consumers" (Oswald, 2012, p. 49). It draws upon semiotic structures and communicates a story that consumers can relate to culturally and can feel addresses their needs. Oswald explained how she uses semiotic analysis by conducting (1) a branding audit of the subject; (2) an analysis of the cultural myths applicable; (3) a strategic positioning grid that maps the findings from (her) research on the subject; (4) a position stance for the brand; and (5) a set of recommendations for a marketing strategy. From this analysis she develops a whole plan of delivery, paying attention to narrative style, making sure there are corresponding graphics and verbiage, even focusing on complementary colors and fonts. She studies the proposed audience for the product, then develops what she calls a "masstige" (p.65), a combination of mass messaging, images and stories representing what that targeted audience views as prestigious. She then invites and enlists the consumer's buy-in and participation in the "masstige" story or narrative. Her research reveals semiotics' links to cultural priorities and 
how semiotics "provides a means of aligning consumer research, cultural environments, and brand communication by articulating the underlying system of codes that they (consumers) all share...the brand actually forms a complex ecosystem of commercial, cultural, and social forces" (p.69-70). Consumers want stories and legends so that they can step into them and satisfy their dreams, at least a little. Executives at Disney Corporation are well aware that the fairytales they promulgate are enjoyed as much by adults as children. The thoroughness of semiotic marketing is reflected from the architectural layout and aesthetics, service, quality to product branding and advertising, all contributing to an atmosphere that reflects the orchestrated effects of all of combined design elements. The semiotics of space, per Oswald, "provides a complex, dialectical account of consumer experiences of their environments and takes account of the intersection of the structural codes regulating the normative dimensions of social spaces .... and defines an epistemological order, an understanding of the world as essentially a world of meanings defined by codes derived from culture, not nature" (p.183). In looking at the thoroughness ascribed to semiotic marketing, we wondered if some of these same principles could be applied to both educational semiotics and their use in disembodied virtual space.

The realization that students need to connect to their cultures and stories prompted us to take a closer look at how marketing and advertising seem to envelop both into successful product buy-in and loyalty. So some of these marketing techniques might work in education for online students too. It seemed that this type of approach needed to be explored in the design of online courseware because currently the online course emphasis is on content and technologies and that is where the locus of attention and budgets are located for most online programs. There may be monies for narratives in the forms of streamed and web-delivered videos, voice-over-Internet protocols, like Skype or Zoom, and perhaps audio clips, but strategic redesigning and tactical embedding of semiotic narratives and metaphors receive little attention in current modes of instructional design. We began designing with semiotics in mind and with intentional plans for structuring courses that included structured semiotics designed to enlist students' cultural and prior knowledge. The hope was that these tools used in on-line course development would better reinforce students' mediation of content materials.

\section{Getting the Picture and the Message}

After excavating these studies among various academic disciplines, we felt there was a preponderance of evidence that supported exploring the use of semiotics as prompts for students searching for signs or shards of experiences related to their lives. They could find these semiotic markers and use them to mediate with the new content materials in their online courses. We conducted several studies in our respective universities (one large private university in the Midwest United States, and one large public university in the Southwest) to see whether the findings of the earlier semiotic studies held true for students in contemporary online courses.

The first study was conducted at the large private university, the researcher received IRB approval and sent out surveys to students taking online courses. One hundred forty-nine (149) students responded. The findings supported students' desire for the inclusion of graphics, supporting metaphors, and stories to help them navigate better through the courses that included graphics (Gannon-Cook, 2012, 2011). Semiotic interventions from that study were integrated into the next online course and the results of the students' feedback again supported the 2011 study's findings, that many students felt more connected in the course with the semiotic interventions. Moreover, there were fewer dropouts in these two online courses than 
in other existing online courses designed without the semiotic graphics and metaphoric "breadcrumbs" (embedded trails of pictures, icons, or metaphors directing students towards their destinations).

The second study approached the use of semiotics somewhat differently. The researcher (from the large private university) designed an instructional design course with graphics that she strategically selected and embedded throughout the course. She scaffolded and sequenced the graphics to correspond to content materials for each course module; she then asked students to complete a survey at the end of the course to see if the course graphics helped them grasp important course principles. She designed the survey as a Likert survey, with five responses ranging from very appropriate (5), appropriate (4), no opinion (3), inappropriate (2) very inappropriate (1), and each question provided three graphics that students were asked to give a ranking to that most clearly represented the term as defined in the course. Her study produced findings that supported the use of strategically-scaffolded graphics to match the increasing course module complexity was effective. What was somewhat surprising was that students had strong responses to what they thought best represented the course definitions. They preferred graphics associated with professional contexts as more appropriate; those graphics associated with nonprofessional contexts were ranked as less appropriate (Ley, Gannon-Cook, 2014). Perhaps the best results of the study were unexpected; at the end of the course the researcher found the student course completion rates to be higher in that course than in other online courses designed for instruction by numerous instructors in a prescribed "canned" format.

We shared our findings and while the two studies differed in their structures, what was similar in both studies was the focus of the studies on using semiotic tools to enhance and facilitate learning. Perhaps, more interesting was that, in addition to both courses' central point of semiotics, both courses experienced higher course completion rates than in other pre-designed and formatted courses at our universities designed without these semiotic tools.

\section{A Virtual Walk Through the Cyber Realm of Online Courses}

We hoped that we could experiment further with ways to include semiotic tools in the design of online courses, and, hopefully, replicate the positive results found in the historical studies' in online and virtual settings. Ultimately, we wanted to see sufficient improvement in student performance and course completion if we were to recommend the inclusion of strategic semiotic tools in online course designs. Our thoughts were that, while the earlier semiotic research (cited previously in this article) was largely passed over in favor of studying newer technologies and social media, resuming the research on the effects of including semiotic tools in online course designs could facilitate improvements in online student retention.

We studied the steps and processes of how students learned in college online courses, starting with their immediate entry into the new course materials without any real segue or explanation of what these new materials would provide to them (other than college credit), and the links to successive content modules and assignments. The basic steps were as follows: students would receive an email with the online course access information which they would then enter to find the course home page and course introduction material. From there a succession of modules with links to course content, discussion conferences, assignments, and often some external links to supporting or additional information. The introduction discussion 
conferences did often contain invitations to students from instructors to provide some detail about themselves as ice breakers. Beyond the introductions, there were seldom any further references back to the students' lives, to any prior knowledge of the students', or to the students' cultural histories. The courses contents were usually programmed to be delivered in ten weeks (quarter-systems) to fifteen weeks (semester-systems). Prescribed formats, learning management systems, varied slightly, but usually contained style sheets that were predictably familiar, ostensibly designed to present course content material. Assignments were generally essay assignments and there were always weekly online discussions that were also required. After looking at the general layouts and reviewing the gist of the contents of many online courses at each university, we realized that the absence of semiotic tools could be a factor contributing to students' loss of interest and higher attrition in in online courses.

\section{Conclusion}

Often online courses are very uniform in look which has merit in providing students with reliable positioning of navigation bars, links, etc. But students often seek more than how to go from one link to another when they begin new courses. They seek something familiar, but not just in course appearance; they seek signposts to show them the path to discovery and new learning. They seek courses that provide richer deeper cultural narratives and course materials that resonate with what they know deep inside. Strategically embedded semiotic tools go beyond providing content. The intentional inclusion of these semiotic tools helps to explain concepts on a subconscious level that learners seem to grasp and absorb more readily than going to websites with just text and links. When these semiotic tools are embedded in online courses, students seem to have higher course completions, which supports research findings that learners who may need those cultural connections might particularly benefit from semiotic tools. Without studying the actual course formats and design factors, like graphics, narratives, and other elements, to discover their impacts on student retention, it is difficult to draw any generalizations about what best helps students to stay involved and complete courses. It is clear that active student engagement is warranted, but it is also likely that there are social, cultural, and semiotic aspects to learning that could, and likely should, be considered to better enlist and retain learners.

Ultimately, utilizing marketing semiotics as a tool for online course design could integrate students' life and cultural experiences with their new virtual learning and invite them to persist and create a new and deeper learning space. While there is no single solution to enlisting and retaining students through to complete online courses, and including more technology and social media might provide some retention improvement, it's time to look beyond just those solutions. Instructional designers should begin looking at some new solutions using primal semiotic tools and experiment with strategically designing courses to include students' cultural and prior knowledge that links to new course content. Then they need to document their results to assess the value of these interventions.

This study looked at how both design development research and the use of marketing semiotics could provide opportunities for greater student involvement and increased student retention. Ultimately, utilizing marketing semiotics as a tool for online course design could integrate students' primal life and cultural experiences with their new virtual learning and invite them to persist and create a new and deeper learning space. There can be lessons learned from reading those signs. 


\section{References}

Allen, I.E., Seaman, J. (2013). Changing course: Ten years of tracking online education in the United States. Babson Survey Research Group and Quahog Research Group, LLC., p.34.

Anglin, G. J., Towers, R. L., Levie, W.H. (1987). Visual message design and learning: The role of static and dynamic illustrations. Retrieved on September 16, 2015 from http://www.aect.org/edtech/ed1/pdf/26.pdf

Anstey, M. (1988). Helping children learn how to learn. Australian Journal of Reading, 11(4), 269-277.

Arnheim, R. (1954). Art and visual perception: A psychology of the creative eye. Berkeley, CA: University of California Press.

Arnheim, R. (1969). Visual thinking. Berkeley, CA: University of California Press.

Arnheim, R. (1974). Virtues and vices of the visual media. In D. R. Olsen, ed. Media and symbols: The forms of expression, communication, and education. The 73d Yearbook of the National Society for the Study of education. Chicago, IL: University of Chicago Press.

Arnheim, R. (1986). New essays on the psychology of art. Berkeley, CA: University of California Press.

Barthes, R. (1977). Rhetoric of the image, in Image/Music/Text, translated by Steven Heath. NY: Hill \& Wang.

Behizadeh, N. (2014). Mitigating the dangers of a single story: Creating large-scale writing assessments aligned with sociocultural theory. Educational Researcher, Vol.43 No.3, pp.125-136. DOI:10.3102/0013189X14529604.

Blumer, H. (1969). Symbolic interactionism: Perspective and method. Englewood Cliffs, NJ: Prentice-Hall, Inc.

Cobb, P., Yackel, E., \& Wood, T. (1992). The contextual nature of teaching: Mathematics and reading instruction in one second-grade classroom. The Elementary School Journal Volume 90, Number 5.

Cowan, K., \& Albers, P. (2006). Semiotic representations: Building complex literacy practices through the arts. The Reading Teacher, 60 (2), 124-137.

Danesi, M. (1993). Vico, metaphor, and the origin of language. Bloomington: Indiana University Press.

Denning, S. (2012). The science of storytelling. Retrieved April 10, 2014, from http://www.forbes.com/sites/stevedenning/2012/03/09/the-science-of-storytelling/

DePriter, Tiffany. 2013. "An investigation of teaching strategy in the distance learning Mathematics classroom." Journal of Educators Online. Accessed March 11, 2015: http://www.thejeo.com/Archives/Volume10Number2/DePriter.pdf

deSaussure, F. (1916/1983). Course in general linguistics. London: Duckworth. (See also Saussure).

deVito, B. (2009). Reading between the lines: The literature review as a form of original research in applied semiotics. International Applied Semiotics Journal, retrieved on April 1, 2012 from http://atwoodpublishing.com/journals/journal.htm

Dwyer, F. M. (1967). The relative effectiveness of varied visual illustrations in complementing programmed instruction. Journal of Experimental Education, 36, 3442.

Dwyer, F. M. (1969). The effect of varying the amount of realistic detail in visual illustrations designed to complement programmed instruction. Programmed Learning and Educational Technology, 6, 147-53. 
Dwyer, F. M. (1972). The effect of overt responses in improving visually programmed science instruction. Journal of Research in Science Teaching, 9, 47-55.

Dwyer, F. M. (1975). On visualized instruction effect of students' entering behaviour. The Journal of Experimental Education, 43, 7-83.

Dwyer, F. M. (1978). Enhancing visualized instruction-recommendations for practitioners. State College, PA: Learning Services.

Dwyer, F. M. (1987). Enhancing visualized instruction-recommendations for practitioners, $2^{\text {nd }}$ ed. State College, PA: Learning Services.

Eco, U. (1976). A theory of semiotics. Bloomington, IN: Indiana University Press.

Eco, U.(1979a). A theory of semiotics. Bloomington, IN: Indiana University Press.

Eco, U. (1979b). The role of the reader: Explorations in the semiotics of texts. Indiana University Press.

Eco, U. (1984). Semiotics and the philosophy of language. Amsterdam: John Benjamin Publishing Company.

Eco, U. (1986). Art and beauty in the middle ages. New Haven CT: Yale University Press.

Eco, U. (1997). Kant and the platypus: Essays on language and cognition. San Diego: Harvest Book, Harcourt, Inc.

Eco, U., Sebeok, T. A., eds. (1984). The sign of three: Dupin, Holmes, Peirce. Bloomington, IN: Indiana University Press.

Eisner, E. W. (1997). Cognition and representation. Phi Delta Kappan, 78(5), 349-353.

Fernlund, P. (1995). Teaching for conceptual change. In B. Blair \& R. Caine (Eds.), Integrative Learning as the Pathway to Teaching Holism, Complexity and Interconnectedness. Lewiston, England: EMText.

Fleming, M. (1967). Classification and analysis of instructional illustrations. $A V$ Communication Review, 15(3), 246-58.

Fleming, M. (1993). Introduction. In M. Fleming and W. H. Levie, eds., Instructional message design: Principles from the behavioral and cognitive sciences. Englewood Cliffs, NJ: Educational Technology.

Ford, M. (1999). Visual representations as conceptual bridges: Modeling of free fall by Galileo and sixth-graders. Unpublished manuscript, NCISLA/Mathematics \& Science, Wisconsin Center for Education Research, University of Wisconsin-Madison.

Gallini, J., Seaman, M., \& Terry, S. (1995). Metaphors and learning new text. Journal of Reading Behavior, 27(2), 187-191.

Gannon-Cook, R. (2011). Lessons learned from semiotics: Social and cultural landmarks for transformative elearning. In Handbook of research on transformative online education and Liberation: Models for social equality, G. Kurubacak and T. Volkan Yuzer, (Eds.). Hershey, PA: IGI Global, pp. 352-359.

Gannon-Cook, R. (2012, August). Restoring washed out bridges so elearners arrive at online course destinations successfully. Creative Education, Vol. 3 Issue 4, p.557-579.

Gannon-Cook, R., \& Ley, K. (2016, January). Past, future and presents...meeting new online challenges with primal marketing solutions. International Journal of Technology and Educational Marketing. (In press).

Gardner, H. (1982). Art, mind, and brain: A cognitive approach to creativity. NY: Basic Books.

Gardner, H., Howard, V.A., \& Perkins, D. (1974). Symbol systems: A philosophical, psychological, and educational investigation. In D. R. Olson, ed., Media and symbols: The forms of expression, communication, and education, $73 d$ Yearbook of the 
National Society for the Study of Education, pp.27-55. Chicago, IL: University of Chicago Press.

Gombrich, E. H. (1969). Art and illusion: A study in the psychology of pictorial representation. Princeton, NJ: Princeton University Press.

Gregory, R., Arenheim, R., Goodman, N. and Gombrich, E.H. (1997), as cited in Ora Silverstein, Concept formation and creativity-from past to future. Selected readings from the Annual Conference of the $28^{\text {th }}$ International Visual Literacy Association, Cheyenne, Wyoming, October, 1996. ED 408 983IR 018396

Kennedy, J. M. (1974). A psychology of picture perception. San Francisco, CA: Jossey-Bass.

Kennedy, J. M. (1984a). Schema theories of perception in aesthetics. Visual Arts Research, 10(2), 30-36.

Kennedy, J. M. (1984b). How minds use pictures. Social research, 51(4), 885-904.

Knowlton, J. Q. (1964). A socio-and psycho-linguistic theory of pictorial communication. Bloomington, IN: Indiana University.

Kosslyn, S. M. (1980). Image and mind. Cambridge, MA: Harvard University Press.

Kosslyn, S. M. (1981). The medium and the message in mental imagery: A theory. Psychological Review, 88, 46-66.

Kress, G., and T. van Leeuwen. (1996). Reading Images: The grammar of visual design. London: Routledge.

Lakoff, G., \& Johnson, M. (1980) Metaphors we live by. Chicago: University of Chicago Press.

Levie, W. H. (1978). A prospectus for instructional research on visual literacy. Educational Communication and Technology Journal, 26, 25-36.

Levie, W. H. (1987). Research on pictures: A guide to the literature. In D. M. Willows and H. A. Hughton, eds. The psychology of illustration: Vol. 1: Basic research. 1-50. NY: Springer.

Levie, W. H., and Dickie, K. E. (1973). The analysis and application of media. In R. M. W. Travers, ed., Second handbook of research on teaching, 858-82. Chicago, IL: Rand McNally.

Levie, W. H., and Lentz, R. (1982). Effects of text illustrations: A review of research. Educational Communication and Technology Journal 30(4), 195-232. Levin, J. R. (1981). On the functions of pictures in prose. In F.J. Pirozzolo and M.C. Wittrock, eds. Neuropsychological and cognitive processes in reading. 203-28. NY: Academic.

Levin, J. R., Anglin, G. J., and Carner, R. N. (1987). On empirically validating functions of pictures in prose. In D. M. Willows and H. A. Houghton, eds. The psychology of illustration, 51-80. NY Springer.

Levin, J. R., and Lesgold, A. M. (1978). On pictures in prose. Educational Communication and Technology Journal, 26, 233-43.

Ley, K., Gannon-Cook, R. (2014a). Continuous improvement: The case for adapting online course templates. In Real Life Distance Education: Case Studies in Practice. Anthony Pena, Al Mizell, (Eds.). Charlotte, SC: IAP Publishing, p. 253-262.

Ley, K. Gannon-Cook, R. (2014b). Vital signs for instructional design. Special Edition of Quarterly Review of Distance Education, 15(1), p.23-32.

Merriam-Webster's Dictionary. (2015). Definition of metaphor. Retrieved from http://www.merriam-webster.com/dictionary/metaphor

Merriam-Webster Dictionary. (2015). Definition of semiotics. Retrieved from http://www.merriam-webster.com/dictionary/semiotics

Miner, R. (2002). Vico, genealogist of modernity. Notre Dame: University of Notre Dame Press. 
Moreno-Armella, L. (1999). On representations and situated tools. Proceedings of the Annual Meeting of the North American Chapter of the International Group for the Psychology of Mathematics Education held in Cuernavaca, Morelos, Mexico, October 23-26, p.96-104. ERIC Document ED 466 384SE 066320.

O’Neil, K. E., (2011). Reading pictures: Developing visual literacy for greater comprehension, Reading Teacher, v. 65, 3, p.214-223.

Oswald, L. (1984). The subject in question: New directions in semiotics and cinema, Semiotica, 48, pp 3-4: 293-317.

Oswald, L. (1996). The space and place of consumption in a material world, Design Issues, $12(1), \mathrm{pp} .48-62$.

Oswald, L. (2010). Marketing hedonics: Toward a psychoanalysis of advertising response, Journal of Marketing Communication, 16(3), pp. 107-131.

Oswald, L. (2012). Marketing semiotics. NY: Oxford University Press.

Peirce, C. S. (1931-1935). The collected papers of Charles Sanders Peirce, vols. 1-6, ed. C.

Hartshorne and P. Weiss. Cambridge, MA: Harvard University Press.

Ross, T., Kena, G., Rathbun, A., Kewal, R., Zhang, J., Kristapovich, P., Manning, E. (2012). Higher education: Gaps in access and persistence study. National Center for Education Statistics. Available from http://nces.ed.gov/pubs2012/2012046.pdf P.184

Sharples, M., Adams, A. Ferguson, R., Gaved, M., McAndrew, P. Rienties, B. Weller, M., Whitelock, D. (2013). Innovative pedagogy. Open University Innovation Report 3, 143.

Skinner, B. F., (1983). A matter of consequences: Part three of an autobiography. New York: New York University Press.

Silverstein, O. (1997). Imagery, concept formation and creativity--from past to future, Selected readings from the Annual Conference of the $28^{\text {th }}$ International Visual Literacy Association, Cheyenne, Wyoming, October, 1996. ED 408 983IR 018396

Stone, D.E, \& Glock, M. D. (1981). How do young adults read directions with and without pictures? Journal of Educational Psychology, 73, 49-26.

Tochon, F. V. (2013). Deep education. Journal for Educators, Teachers and Trainers, Vol. 1, p.14. Retrieved on November 1, 2014 from http://www.ugr.es/ jett/articulo.php?id=1

Verene, D. (1993). Metaphysical narration, science, and symbolic form. Review of Metaphysics, 47, 115-132.

Wade, S.E. \& Adams, R.B. (1990). Effects of importance of interest on recall of biographical text. Journal of Reading Behavior, 22, 331-352.

Youngs, S., Serafini, F. (2013). Discussing picture books across perceptual, structural and ideological perspectives. Journal of Language \& Literacy Education, Vol. 9, 1, $185-$ 200.

$\mathrm{Yu}, \mathrm{H}$. (2013). Human brains function culturally: Semiosis under the culture-driven view. The American Journal of Semiotics, Vol. 29, 1-4, p. 135-148.

Zaltman, M. (1997). Lieber, R. (Ed.). Storytelling: A new way to get close to your customers. Fortune, 2(1), 102.

Zaltman, G., Colter, R.H. (1995). Seeing the voice of the customer: metaphor-based advertising research, Journal of Advertising Research, 35(4), 35-51.

Zaltman, Gerald, and Zaltman, L. (2008). Marketing metaphoria: What deep metaphors reveal about the minds of consumers. Harvard Business School Press, 2008. 